\title{
Presentación EURE 100
}

\section{Revisitando una historia}

$\mathrm{L}$ a aparición del número 100 de EURE constituye una instancia apropiada para realizar algunas reflexiones sobre la evolución de esta revista a la luz de lo que ella se propuso inicialmente y de los resultados obtenidos a lo largo de más de 37 años de vida; y, sobre esa base, esbozar algunos de los desafíos que es posible ahora vislumbrar para los años venideros.

Para iniciar estas reflexiones, cabe recordar que EURE comenzó a ser publicada en octubre de 1970 por el Centro Interdisciplinario de Desarrollo Urbano y Regional (CIDU) de la Pontificia Universidad Católica de Chile (PUC), el cual tenía como objetivo constituirse como el órgano de los centros de estudios urbanos y regionales de la Comisión de Desarrollo Urbano y Regional del Consejo Latino Americano de Ciencias Sociales (CLACSO). Así, se planteó que EURE tendría el propósito de dar a conocer las investigaciones realizadas en los programas permanentes de dichos centros y, con ello, "estimular el estudio de problemas cada vez más relevantes" en el campo de lo urbano y regional.

En el marco de los complejos y dramáticos cambios que se produjeron en el escenario político latinoamericano, especialmente en el sur de nuestro continente y en Chile en particular, para poder asegurar su continuidad, la publicación de EURE fue asumida posteriormente por el Instituto de Planificación del Desarrollo Urbano y Regional (CIDU-IPU) de la PUC y, finalmente, y hasta el día de hoy, por el Instituto de Estudios Urbanos y Territoriales (IEU+T) de esta misma casa universitaria.

Estos antecedentes permiten destacar que, desde sus orígenes, la revista fue concebida como un medio de alcance y contenido internacional y, particularmente, latinoamericano, lo cual fue establecido como uno de los rasgos básicos de las señas de identidad que se han mantenido y reafirmado a lo largo de todos estos años. Con esta orientación, EURE ha venido siendo publicada en forma regular desde su fundación, lo que le ha permitido ubicarse como la revista de mayor antigüedad de América Latina en este ámbito de especialización. A lo largo de este período, EURE ha podido recoger más de 500 artículos de diversa procedencia geográfica, pero donde ha primado la autoría de investigadores latinoamericanos.

\section{EURE y sus tiempos iniciales}

EURE apareció en el momento en el que los temas relativos al "desarrollo económico y social" se ubicaron en el centro del debate político latinoamericano, cuando, bajo el impulso de las propuestas de la CEPAL y de la "Alianza para el Progreso", las ideas sobre "planificación del desarrollo" alcanzaron su apogeo. En efecto, correspondió a un momento de la evolución de esta parte del mundo en el que el tema de la planificación se presentaba, cuando menos en el ámbito de la retórica política, como el camino obligado para poder superar el subdesarrollo.

En ese momento, y especialmente durante la década de los años sesenta del siglo pasado, se había formado en estos países un clima intelectual y político favorable a lo que entonces se entendió como el camino apropiado para promover el "desarrollo económico y social", objetivo cuya factibilidad entonces no se cuestionaba mayormente. Las ideas asociadas a este clima produjeron en ciertos medios intelectuales y políticos un ambiente de optimismo y de esperanza sobre la posible evolución futura de estos países. En este sentido, podría decirse que América Latina vivió a su manera un ambiente equivalente al que se había generado en los países desarrollados en las tres décadas posteriores a la II Guerra Mundial, que llegaron a merecer la denominación de los "treinta gloriosos". 
Fue bajo ese impulso que la dimensión urbano-regional del desarrollo comenzó a cobrar relevancia en la agenda de los organismos relacionados con el desarrollo y la planificación, tanto a nivel nacional como internacional. Como consecuencia de ello, numerosos estudios, debates y actividades buscaron profundizar el conocimiento sobre los orígenes y la evolución de los problemas urbanos y territoriales, además de identificar los caminos más adecuados para enfrentarlos. Fue también en esa época, y bajo la influencia de las ideas dominantes en ella, cuando las propuestas del urbanismo racionalista, sustentadas principalmente por el pensamiento de los Congresos Internacionales de Arquitectura Moderna (CIAM) y, en especial, de la Carta de Atenas, lograron su mayor predicamento y se constituyeron en un componente central de las discusiones sobre gestión urbana en estos países.

No obstante, en forma contrapuesta a estos esfuerzos, hacia fines de la década de los años sesenta, los síntomas del agotamiento del modelo keynesiano industrial-desarrollista se hicieron evidentes al intensificarse un conjunto de desequilibrios que ningún gobierno alcanzó a controlar plenamente. Al mismo tiempo, comenzaron a hacerse presentes los gérmenes de una revuelta social que, bajo diversas formas, habrían de prolongarse por bastante tiempo, con consecuencias políticas y sociales entonces imprevisibles.

EURE nace justamente cuando el ocaso de esta fase era evidente, y cuando diversos problemas urbanos y territoriales, en especial los relativos a la acentuación de los desequilibrios regionales y a la concentración metropolitana, mostraban una tendencia a agudizarse en muchos de estos países. Los trabajos que la revista recogió desde sus números iniciales constituyen un testimonio claro de esa situación, donde predominó el análisis crítico y la aproximación multidisciplinaria. En esa dirección, puede observarse un continuo esfuerzo por identificar y analizar las principales implicancias económicas, sociales y políticas de la cuestión urbano-regional en vinculación con la dinámica industrial-desarrollista prevaleciente en estos países. Para ello, EURE convocó a los autores más importantes de esta corriente, cuyos análisis, reflexiones y propuestas documentan las principales preocupaciones de este momento y conforman un invalorable testimonio sobre los enfoques entonces dominantes y sobre su evolución en esa fase de la historia de estos países.

\section{Un difícil interregno}

Los años que siguieron al agotamiento del modelo industrial-desarrollista, con todas sus consecuencias políticas, sociales y económicas, fueron particularmente difíciles para la acción y la discusión académica e intelectual en toda América Latina, pero especialmente en los países de la parte sur del continente, donde la ruptura democrática tuvo carácter generalizado, en muchos casos con consecuencias sociales extremadamente dolorosas.

Pese a esta compleja situación, EURE logró mantener su continuidad y regularidad, pero el esfuerzo que fue necesario realizar para preservar y mantener la orientación, el contenido y la calidad de la revista, planteó grandes dificultades y exigió una especial dedicación de parte del equipo editorial que debió cumplir esta tarea durante esos años. Para ello, resultó fundamental la generosa colaboración de un grupo relativamente numeroso de investigadores de distintos países latinoamericanos, que comprendieron la importancia de contar con este medio de comunicación, aun con las limitaciones que imponían las circunstancias políticas de ese momento.

Fue así que, a lo largo de esos años, la revista pudo continuar ofreciendo sus aportes sobre la evolución de la dinámica urbana y territorial, en un período en el que los cambios que la caracterizaban comenzaban a exigir nuevos enfoques, así como un replanteo conceptual que permitiese una mejor comprensión de las condiciones y factores que se estaban perfilando en el mundo entero, bajo los efectos de la informacionalización y la globalización. Esta dinámica estaba llevando a la conformación de un escenario sustantivamente diferente al dominante en el período anterior, por lo que resultaba de 
fundamental importancia identificar y explicar las tendencias centrales que comenzaban a caracterizar una nueva dinámica urbano-territorial y, así, perfilar los cursos de acción posibles frente a ella.

\section{Nuevos temas, nuevos enfoques}

En las condiciones que se afirmaron con la recuperación de la democracia, en la mayor parte de los países de la región se reactivó la discusión sobre los problemas relativos al desarrollo territorial. Esto, a medida que en esta parte del mundo también comenzaba a imponerse una dinámica urbano-territorial derivada de la aplicación de políticas sustentadas en fundamentos teórico-ideológicos muy distintos a los que se habían impuesto en la posguerra. En lo fundamental, era posible observar que, en el marco de los cambios producidos en la dinámica económica mundial bajo el impulso de la globalización, la mayor parte de los países latinoamericanos comenzó a implementar radicales procesos de reestructuración productiva, como camino para encontrar una salida al agotamiento del modelo industrial-desarrollista. Al mismo tiempo, el discurso de la "planificación del desarrollo" fue desplazado por enfoques sustentados en la comprensión de que los procesos sociales observables en sociedades democráticas de complejidad creciente, son modulados por las acciones de una multitud de actores sociales, motivados por estrategias frecuentemente contradictorias. Por lo tanto, requieren de esfuerzos de coordinación y compatibilización capaces de orientarlas hacia la consecución de objetivos consensuados, tarea ineludible para mejorar la gobernabilidad de los respectivos sistemas sociales locales o nacionales.

A medida que estas ideas y enfoques ganaban espacio, ya hacia fines del siglo pasado comenzó a reactivarse el contacto, la comunicación y el intercambio entre los investigadores urbano-regionales que habían permanecido estancados por algunos años. Con ello, se intensificaron las investigaciones sobre esa nueva realidad, constituyéndose numerosas redes internacionales que cumplieron con la tarea de promover la investigación, la comunicación y la discusión sobre estos temas y problemas, cuestión que intensifica la producción intelectual en torno a esta nueva realidad, aunque bajo enfoques y perspectivas diferentes.

En ese contexto, fueron ganando importancia temas como los relativos al crecimiento endógeno, a la organización territorial en red, al papel de las innovaciones en el desarrollo productivo local, a las tendencias en la organización socio-territorial con la aparición de nuevas formas de exclusión social, a la reactivación del crecimiento económico metropolitano acompañado por incontrolables procesos de expansión metropolitana y periurbanización, a las nuevas estrategias de competitividad territorial y, en especial, urbana, entre muchos otros.

\section{Eure en una dinámica de cambios}

Bajo esta dinámica, más allá de los profundos cambios que han afectado al enfoque y al contenido de los trabajos publicados por EURE, los últimos años también han presionado por un replanteamiento y reestructuración de diversos aspectos relativos a su organización y su funcionamiento. Uno de los hechos que ha tenido una importante incidencia en esta dirección, ha sido el aumento significativo del flujo de propuestas de artículos, procedentes fundamentalmente del medio latinoamericano, tanto en lengua castellana como portuguesa, situación estimulada por el prestigio ganado en sus más de treinta años de publicación ininterrumpida, así como por el atractivo que tiene para numerosos investigadores publicar en una revista con múltiples indizaciones. Esto ha planteado nuevos criterios y procedimientos para la confección de cada número y para la selección del material respectivo, conforme a criterios mucho más rigurosos para la selección del material a publicar.

Así, EURE ha tenido que ajustarse al imperativo de los mecanismos, procedimientos, criterios y normas establecidos con alcance internacional para la producción y edición de publicaciones de perfil científico, que son aceptados y exigidos por la mayor parte de las indizaciones. Al mismo tiempo que 
$\overline{\text { Presentación }}$

se avanzaba en el proceso de adaptación a esta tendencia, EURE tuvo que encarar su incorporación al mundo de las ediciones virtuales, cuestión que ha generado la coexistencia de la tradicional edición en papel con una versión electrónica simultánea de acceso abierto, impactando profundamente la tradicional política de promoción y difusión de la Revista.

En otras palabras, la publicación de revistas de esta naturaleza se ha transformado, a partir de la propia dinámica impuesta por la globalización y la informacionalización, en un fenómeno regido por criterios y normas de vigencia y aceptación universal, que impone nuevas y complejas exigencias a cada una de ellas. Concretamente, para el caso de EURE, esto ha significado que su elaboración y publicación deban desarrollarse bajo exigencias y condiciones radicalmente diferentes a las que imperaban al momento de su creación. Este proceso, al cual se ha ido adscribiendo, todavía exige un conjunto de cambios y ajustes necesarios que permitan su plena inmersión en el nuevo escenario, los cuales comenzarán a desarrollarse con los primeros números del año próximo; reconociendo, en cualquier caso, que esa puesta al día se realizará reforzando su vocación original de constituirse en un crisol del pensamiento latinoamericano en torno a las cuestiones urbano-territoriales de esta parte del mundo. 